\title{
Cytotoxicity of Structurally Diverse Anthranoids and Correlation with Mechanism of Action and Side Effects
}

\author{
Daniel P. Demarque ${ }^{1}$, Rui M. P. da Silva ${ }^{2}$, Leandro F. Santos ${ }^{1}$, Andréia M. Leopoldino ${ }^{1}$, Enilza M. Espreafico ${ }^{2}$ and \\ Norberto P. Lopes ${ }^{1}$ \\ ${ }^{1}$ Department of Physics and Chemistry, School of Pharmaceutical Sciences of Ribeirão Preto, University of São Paulo, \\ Ribeirão Preto - SP, Brazil. ${ }^{2}$ Department of Cell and Molecular Biology and Pathogenic Bioagents, Faculty of Medicine \\ of Ribeirão Preto, University of São Paulo, Ribeirao Preto - SP, Brazil.
}

Received, July 15, 2018; Revised, August 3, 2018; Accepted, September 6, 2018 ; Published, September 7, 2018.

\begin{abstract}
The purpose of this contribution is to evaluate the cytotoxicity and apoptosis inducing ability of structurally diverse anthraquinones to establish a relationship between structure and toxicity. Besides the wide spread use of anthraquinones in pharmacological drugs for constipation and non-prescription dietary supplements for weight loss, extracts are still commercialized as crude extracts and long-term side effects are still relevant. In this work we developed a method to quantify the cascarosides isolated from Rhamnus purshiana (Cascara Sagrada) using LC-MS/MS and evaluated the effects of this extract and isolated compounds on cellular viability using NOK-SI, HeLa, and T98G cell lineages. Apoptosis inducing ability was also analyzed via evaluating key-proteins involved in apoptosis pathways. Using cascarosides isolated from bark extracts, we found that the presence of glucose moieties in the chemical structure reduced the toxicity. This communication reviewed the mechanisms of action, toxicity of anthraquinones and correlated the toxicity with chemical structures of cascarosides. Results indicate that cascarosides-enriched cascara extract, as well as glycosylated anthraquinones, may have some beneficial effects for laxative action of herbal medicines. Considering our results, a cascarosides-enrichment in cascara extract is recommended.
\end{abstract}

\section{INTRODUCTION}

Anthraquinones are extensively present in nature, found in plants, bacteria, fungi, and insects. They are widely used as pharmacological drugs for constipation and as non-prescription dietary supplements for weight loss. Currently, these compounds are used to treat a variety of conditions because of their wide ranging biological activities, including anti-inflammatory, antifungal, antibacterial, antiviral, and antiarthritic actions (1).

Due to the cytotoxic action of some anthraquinone components, as doxorubicin (natural), daunorubicin (natural) and valrubicin (semisynthetic), several medicines have been developed to treat cancer (1-3). One important mechanism of action for cytotoxic agents used in cancer treatment is apoptosis induction. However, apoptosis is also responsible for the long-term side effects - as mucosa darkening - of anthraquinonerich plants.

The mucosa darkening, also known as pseudomelanosis coli, is a lipofuscin-like pigment found in macrophages from colonic lamina propria. The melanosis coli has been linked to the chronic use of laxative/purgative anthranoid-rich plants $(4,5)$. Despite effective laxative action of anthraquinonerich plants, clinical studies demonstrated that $73.4 \%$ of patients who chronically used anthranoids laxatives had melanosis coli, showing a clear association between anthraquinones and colon darkening (6). Histological studies have shown that a large number of apoptotic bodies are not caused by natural renewal, but by laxative action, suggesting that melanic substances are formed by the action of anthraquinones (7). Chen et al. (8) proposed a melanosis-forming mechanism that correlated the accumulation of pigments to the long-term use of these natural compounds. When such compounds enter the colon, they produce a laxative effect and damage the epithelial cells. These cells release TNF$\alpha$ for the cell renewal induction mechanism via triggering apoptosis. Furthermore, damaged epithelial cells are phagocytized by macrophages, which migrate to lamina propria of the epithelium. In the lamina propria, the apoptotic bodies become lipofuscin, giving rise to black patches that darken the colon. With chronic use, such damage causes immunotoxicity and results in inflammation.

Although some studies have suggested that glycosides-anthraquinones are less toxic than the corresponding aglycone, these studies did not

Corresponding Author: N. P. Lopes, Núcleo de Pesquisa em Produtos Naturais e Sintéticos, Departamento de Física e Química, Faculdade de Ciências Farmacêuticas de Ribeirão Preto - SP, Universidade de São Paulo, Brazil, E-mail: npelopes@gmail.com 
characterize the toxicity of cascarosides present in cascara sagrada. Furthermore, it remains unknown if these compounds are responsible for melanosis coli or trigger apoptotic pathways in the cells. Understanding the level of toxicity and potency of different classes of these (anthraquinone) compounds could be an alternative to developing more effective medicines with fewer side effects. Thus, in this contribution, we evaluate the cytotoxicity and apoptosis induction of these compounds to establish a structure-activity relationship. We also review the mechanisms of action and toxicity of anthraquinones.

\section{MATERIAL AND METHODS}

\section{General}

HPLC-grade methanol (J.T. Baker), trifluoroacetic acid (TFA, J.T. Baker), formic acid (J.T. Baker) and ultrapure water (Millipore, MA, USA) were used in HPLC and mass spectrometry analysis. We obtained commercial powder of cascara sagrada $(R$. purshiana) bark from Santos Flora (lot number CASC01/1210) and extracted it through percolation with ethanol (CrEx). The cascarosides A, B, C, D, $10 \mathrm{OH}-\mathrm{A}$ and $10 \mathrm{OH}-\mathrm{B}$ were isolated and the ethyl acetate phase $(\mathrm{EtAcPh})$ was obtained according to a previous work (9).

\section{Quantification of cascarosides in CrEx and EtAcPh}

The quantification of the isolated compounds in the extracts were done using a HPLC Shimadzu (LC20AD) coupled with an ESI triple quadrupole mass spectrometer (ABSciex API 3200). Epigallocatechin was used as an internal standard. For chromatographic separation, a column Supelco Ascentis Express $\mathrm{C}_{18}(5 \mathrm{~cm} \times 2.1 \mathrm{~mm}, 2 \mu \mathrm{m}$ of particle size) was used, coupled with a pre-column with the same material. The mobile phases were optimized to obtain the best signal/noise ratio and water and methanol (both with $0.1 \%$ of formic acid) were adopted. The elution method was initiated with $5 \%$ of $\mathrm{B}$, kept isocratic for $0.7 \mathrm{~min}$, which was then increased to $35 \%$ for $1 \mathrm{~min}$ and to $45 \%$ for $5 \mathrm{~min}$. After this period, a new gradient until $100 \%$ was adopted for $7.5 \mathrm{~min}$. $3.5 \mathrm{~min}$ were added to the method to wash and stabilize the column. The injection volume was $15 \mu \mathrm{L}$, the column temperature was $45^{\circ} \mathrm{C}$, and the autosampler temperature was $5^{\circ} \mathrm{C}$. The negative ionization mode was employed and the ionization source parameters were CUR 12 (Curtain Gas), source temperature $450{ }^{\circ} \mathrm{C}$, ionization voltage (IS) $-4500 \mathrm{~V}$, CAD gas (Collisionally-activated dissociation gas) 8, Gas1 (nebulization gas) 50 and Gas2 (turbo heaters gas)
50. The parameters DP (declustering potential), EP (entrance potential), CEP (collision cell entrance potential), CE (collision energy), CXP (collision cell exit potential) and DT (Dwell time, monitoring time for each transition keeping around 18 scans/peak) were optimized for each monitored transition and are shown in Table 1.

The quantification methodology was validated for precision (curve with 9 points and 6 replicates each), inter-run accuracy (6 replicates in 9 points), selectivity, and linearity. The assumed concentrations were $10,20,50,100,125,250,375$, $500,1000 \mathrm{ng} / \mathrm{ml}$. The extracts and phases were diluted in the $25 \mathrm{mg} / \mathrm{ml}$ concentration and then diluted in the same curve conditions.

\section{Viability assay}

For viability assay, NOK-SI (normal oral keratinocyte spontaneously immortalized) (10), HeLa (human cervix adenocarcinoma) and T98G (human glioblastoma multiforme) cell lineages were cultured in DMEM (Sigma-Aldrich), K-562 (human chronic myelogenous leukemia) and HL-60 cells (human acute promyelocytic leukemia) in RPMI (Sigma-Aldrich). Both were supplemented with $10 \%$ fetal bovine serum (FBS-GIBCO) and antibiotics (Sigma-Aldrich) at $37^{\circ} \mathrm{C}$, and $5 \% \mathrm{CO}_{2}$. Cells were seeded in 96-well plates $\left(1 \times 10^{4}\right.$ cells/well) and, after 24 hours, they were exposed to different concentrations of the compounds and the crude extract, as indicated in the Figure 1 legend. HeLa, T98G, K-562 and HL-60 cells were incubated for $24 \mathrm{~h}$, while NOK-SI cells incubated for $48 \mathrm{~h}$ with the compounds, before determination of cytotoxicity by the alamarBlue ${ }^{\circledR}$ cell viability assay. The oxidized alamarBlue reagent was added at a final concentration of $0.01 \mathrm{mg} / \mathrm{mL}$, and cells were maintained for $3 \mathrm{~h}$ in the standard culture conditions. The fluorescence from reduced alamarBlue reagent was measured using a microplate reader at 530/25 $\mathrm{nm}$ emission and 590/35 $\mathrm{nm}$ excitation wavelengths. The results are presented as the percentage of viable cells in relation to the control of each compound (vehicle). A negative control, containing the medium with no cells to determine baseline signal, as well as a positive control of cell death induction (3\% DMSO), were included in all assays. A one-way Anova was used, and results with $p<0.05$ were considered statistically significant.

\section{Apoptosis analysis}

For apoptosis analysis, NOK-SI cells were cultured in $100 \mathrm{~mm}^{3}$ culture plates $\left(9 \times 10^{5}\right.$ cells). After $24 \mathrm{~h}$, the isolated compounds or extracts were added (300 $\mu \mathrm{g} / \mathrm{mL}$ ) and maintained for $48 \mathrm{~h}$. Cellular protein extracts were obtained with CelLytic reagent 
Table 1. MS parameters optimized for cascarosides quantification (QT - quantification; Conf - confirmation).

\begin{tabular}{cccccccccc}
\hline & & Q1 & Q3 & DT & DP & EP & CEP & CE & CXP \\
\hline Casc A/B & QT & 579.0 & 297.0 & 15 & -61 & -10 & -54 & -51 & -8 \\
& Conf & 579.0 & 459.0 & 15 & -61 & -10 & -54 & -39 & -7 \\
\hline \multirow{2}{*}{ Casc 10-H A/B } & QT & 595.0 & 269.0 & 15 & -60 & -10 & -54.5 & -64 & -6 \\
& Conf & 595.0 & 432.0 & 15 & -60 & -10 & -54.5 & -34 & -15 \\
\hline \multirow{2}{*}{ Casc C/D } & QT & 563.0 & 281.0 & 15 & -53 & -10 & -53.5 & -52 & -52 \\
& Conf & 563.0 & 443.5 & 15 & -53 & -10 & -53.5 & -41 & -13 \\
\hline \multirow{2}{*}{ Epi } & QT & 457.0 & 169.0 & 20 & -40 & -4 & -50.6 & -28 & 0 \\
& Conf & 457.0 & 125.0 & 20 & -40 & -4 & -50.6 & -52 & 0 \\
\hline
\end{tabular}

(Sigma-Aldrich) containing protease and phosphatase inhibitors (Sigma-Aldrich). Protein concentration was determined by the Bradford protein assay (Bio-Rad). Cellular protein extracts $(30 \mu \mathrm{g})$ were electrophoretically separated in 10\% sodium-dodecyl sulfate polyacrylamide gels (SDSPAGE) and transferred to PVDF membrane (Ge HealthCare). Membranes were blocked with a 5\% nonfat dry milk (Bio-Rad) in Tris buffer containing 10\% Tween-20 (TBST). Primary antibodies used were against PARP (PARP (46D11) Rabbit mAb \# 9532), RIP1 (RIP (D94C12) XP ${ }^{\circledR}$ Rabbit mAb \# 3493), caspase-8 (caspase-8 (1C12) Mouse mAb \# 9746), caspase-3 (caspase-3 (8G10) Rabbit mAb \# 9665) and calnexin (calnexin (C5C9) Rabbit mAb \# 2679). Immunocomplexes were visualized using the Enhanced chemiluminescence Western blotting detection reagents (GE HealthCare).

\section{RESULTS}

\section{Quantification of cascarosides}

The analytical method was validated for cascarosides quantification. In Table 2, the cascarosides content of CasEtAcPh and $\mathrm{CasCrEx}$ are reported. The cascarosides levels in CasEtAcPh are lower than in CasCrEx.

Table 2. Cascarosides content (percentage) in CasEtAcPh and CasCrEx.

\begin{tabular}{ccc}
\hline & CasEtAcPh $(\%)$ & CasCrEx $(\%)$ \\
\hline Casc A & 0.32 & 3.31 \\
Casc B & 0.37 & 5.78 \\
Casc C & 0.32 & 1.15 \\
Casc D & 0.23 & 2.79 \\
10H-A & 0.42 & 4.54 \\
10H-B & 0.52 & 1.63 \\
Total & 2.17 & 19.21 \\
\hline
\end{tabular}

The world health organization (WHO) recommends a daily dosage varying from 0.3 to $1 \mathrm{~g}$ of crude extract, standardized to contain 20 to $30 \mathrm{mg}$ of cascaroside A. Therefore, the extract should have between $2 \%$ to $10 \%$ of cascaroside A for a $70 \mathrm{~kg}$ person. The levels of CasCrEx found in this study are consistent with the international recommendations.

\section{Viability assay}

In order to understand the contribution of each compound class to the extract toxicity, we performed in vitro studies with human cell lineages. The first compounds tested were the cascarosides, which did not show any toxicity in NOK-SI cells in the tested concentrations (Figure 1A). The $\mathrm{CasEtAcPh}$ and $\mathrm{CasCrEx}$ did show toxicity. We expanded the structures tested, considering studies that have shown toxicity for some isolated compounds present in cascara extract. So, emodin, anthralin and aloin were tested and showed toxicity in NOK-SI cells (Figure 1A). The initial results suggested that the more polar the compounds were, the less toxic they would be.

\section{Apoptosis analysis}

To demonstrate the apoptosis inducing ability of toxic compounds and extracts found in the previous assay, we analyzed pro-caspase-3, pro-caspase- 8 and PARP proteins (11) through Western blotting (Figure 1B). In addition, we analyzed the levels of receptor-interacting protein 1 (RIP) because RIP1 full length has been appointed as an anti-apoptotic protein (12). Our results showed decreased procaspase- 8 and pro-caspase-3 (intact protein) accompanied by cleavage of poly(ADP-ribose) polymerase (PARP) and decreased RIP1 (full length), suggesting apoptosis activation by CasCruEx (Figure 1B). Additionally, the high intensity of cleaved PARP (89 $\mathrm{kDa}$ ) compared to PARP (full length; $116 \mathrm{kDa}$ ), accompanied by the loss of pro-caspase- 3 and pro-caspase- 8 and the decrease of RIP1 in cells incubated with Aloin, Anthralin, and Emodin suggest apoptosis and corroborate with the higher cytotoxic profile presented in Figure 1A. 
A. Viability assay
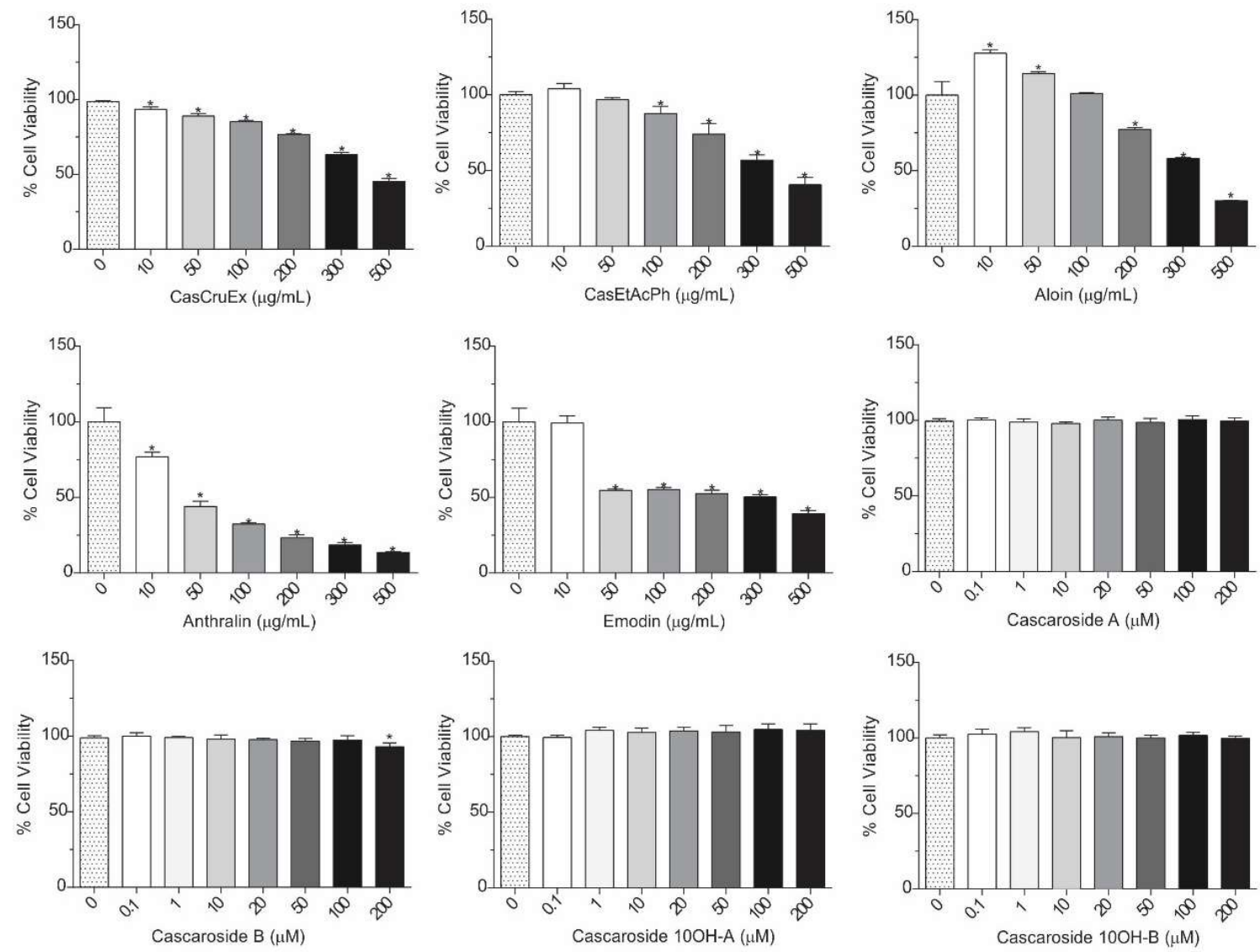

B. Caspase assay

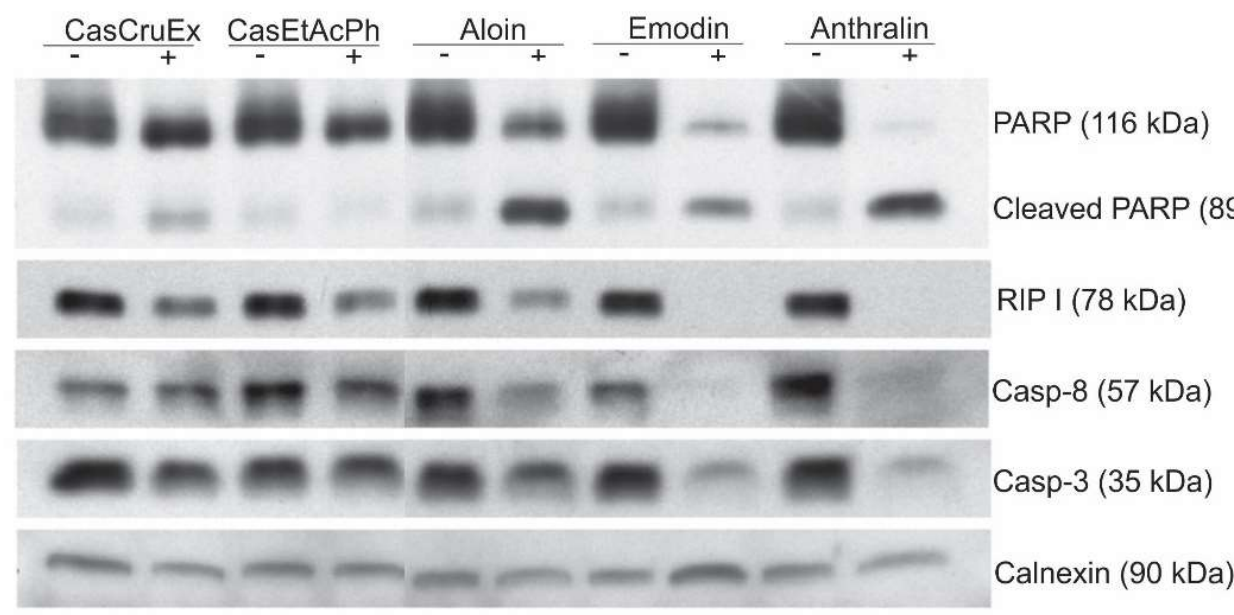

Figure 1: (A) Cell viability of NOK-SI cells at different concentrations of extracts and isolated compounds from cascara sagrada by alamarBlue viability assay. (B) NOK-SI cells were incubated with $300 \mu \mathrm{M}$ of each compound (Aloin, Emodin and Anthralin) or extracts (CasCruEx and CasEtAcPh) for $48 \mathrm{~h}$. Caspase-8, caspase-3, PARP and RIP1 proteins were analyzed through Western blotting. Calnexin protein was used as a loading control. (-) indicates absence of compound; $(+)$ indicates presence of compound. PARP: poly(ADP-ribose) polymerase; RIP: Receptor-interacting protein (RIP); Casp: caspase. $(0.1,1,10,20,50,100$ and $200 \mu \mathrm{M}$ for the cascarosides A and B; 0, 10, 50, 100, 200, 300, $500 \mu \mathrm{g} / \mathrm{mL}$ for the crude extract, aqueous phase, Aloin, Emodin and Anthralin). NOK-SI cell assays were tested at the following concentrations 1, 10, $50,100,500$ and $1000 \mu \mathrm{M}$ for the cascarosides $\mathrm{A}$ and $\mathrm{B}$, and 1, 10, 50, 100, 500 and $1000 \mu \mathrm{g} / \mathrm{mL}$ for CasCruEx and CasEtAcPh). 


\section{Tumoral cytotoxicity assay}

To evaluate the potential antitumor effect of the compounds, we performed in vitro cell viability assays in four different human tumor cell lines. The CasCrEx showed high cytotoxicity in human leukemia cell lines compared to HeLa and T98G cells. The cascarosides A and B did not show significant cytotoxicity in HeLa and T98G cells, however, we observed moderate cytotoxicity in K562 and high cytotoxicity in HL-60, especially for cascaroside $\mathrm{B}\left(\mathrm{IC}_{50} 20.81 \mu \mathrm{M}\right)$. The results are described in Table 3.

\section{DISCUSSION}

In fact, it has been proven that some anthraquinones can activate apoptosis in cells. Apoptosis is programmed cell death, which is believed to trigger cell renewal. The goal of apoptosis is to get rid of infected or damaged cells (13). Apoptosis can be triggered by extrinsic (via death receptor) and intrinsic (via mitochondrial) pathways. The extrinsic pathways are triggered by external stimulation (such as TNF), which activate death receptors and caspase cascades, causing cell death. The intrinsic apoptotic pathways, which are often deregulated in cancer, are related to cytokine deprivation, DNA damage, and endoplasmic reticular stress. Both pathways converge to a common pathway, resulting in cleavage of pro-caspase-3 (decreasing this intact form), poly(ADP-ribose) polymerase (PARP) cleavage, and cell death (14). Our results in Figure 1 indicate that the anthraquinone core is responsible for the toxic activity of cascara sagrada extract.

The structure-activity relationship shows that the presence of glucose units in the molecule reduces the toxicity, while anthrones and anthraquinones with any glucose units show a similar toxic profile (Figure $2)$. The aglycones are the active compounds in anthranoid extracts. Although (ox)anthranoids are the active compounds, it is recommended to avoid them in cascara extract. Cascara bark should be stored for at least one year prior to use, to reduce anthranoid levels (which oxidize to corresponding anthraquinones). The use of fresh plants causes "griping" (spasmodic pains in the bowels) and emetic side effects. Despite this recommendation, aglycone anthrones and anthraquinones seem to have similar toxicity according to our results.

Although aglycones are responsible for laxative activity, they are also responsible for the toxic effects found in anthraquinone-rich extracts $(15,16)$. In fact, glycosylated anthrones - such as cascarosides and barbaloin - act as prodrugs and the intestinal flora has the crucial role of releasing the active aglycones $(17,18)$. Akao et al. (19) investigated the laxative action of glycosylated anthranoid Barbaloin, and found that it did not cause diarrhea in rats. However, after association with Eubacterium sp. - a human intestinal bacteria capable of transforming barbaloin (glycosylated) to aloe-emodin (aglycone) - diarrhea was clearly induced. This also occurs with other glycosylated anthranoids as cascarosides (20) and sennosides (18). Furthermore, both $\mathrm{C}$ - and O- bonds can be broken by intestinal bacteria, even though there is a restricted number of strains that can break C-bonds.

The comparison between anthraquinones and their glycosylated form as laxatives indicates that glycosylated ones are more potent. This assumption is supported by the polarity concept: glycosylated compounds are more polar and tend to stay in intestinal lumen. Pharmacokinetic studies support that glucuronides remain unaffected during transit in the gastrointestinal tract, which can lead to microflora releasing the active aglycone in the colon. Assuming that glucosyl anthraquinones are less likely to enter the systemic circulation and, to consequently be metabolized, their presence in intestinal lumen allows them to exert a higher effect than anthraquinones. Additionally, the FDA recommends using 15 to 20 times more concentrated anthraquinones than glycosides anthraquinones (15).

Table 3. $\mathrm{IC}_{50}$ values of CasCrEx $(\mu \mathrm{g} / \mathrm{mL})$ and cascarosides $\mathrm{A}$ and $\mathrm{B}(\boldsymbol{\mu M})$ after $24 \mathrm{~h}$ treatment against different human tumoral cell lines.

\begin{tabular}{cccccc}
\hline & & & & \multicolumn{2}{c}{$\mathrm{IC}_{50}(\mu \mathrm{M})$} \\
\cline { 4 - 6 } Cell line & Classification & Organism & CasCrEx $^{*}$ & Casc A & Casc B \\
\hline HeLa & cervix adenocarcinoma & Human & 124.6 & $>1000$ & $>1000$ \\
T98G & glioblastoma multiforme & Human & 129.1 & $>1000$ & $>1000$ \\
K-562 & chronic myelogenous leukemia & Human & 7.78 & 641.1 & 536.8 \\
HL-60 & acute promyelocytic leukemia & Human & 2.93 & 103.3 & 20.81 \\
\hline * CasCrEx IC50 values are expressed in $\boldsymbol{\mu g} / \mathbf{m L}$ & & & &
\end{tabular}




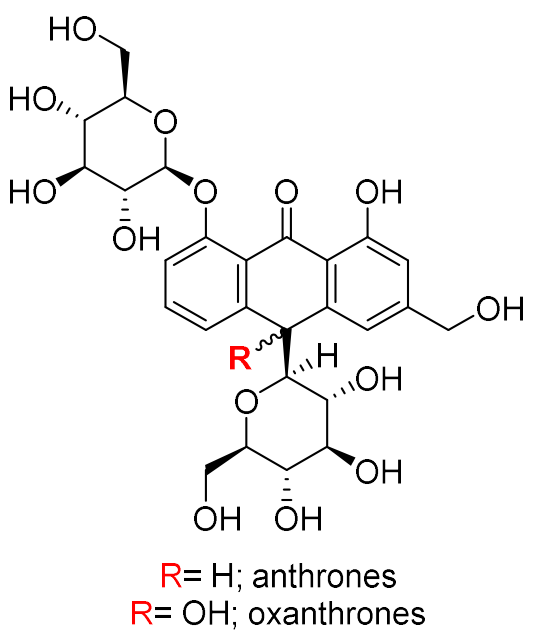

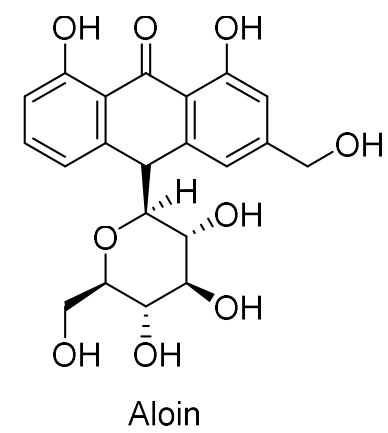

Aloin<smiles>O=C1c2c(O)cccc2Cc2cccc(Br)c21</smiles><smiles>Cc1cc(O)c2c(c1)C(=O)c1cc(O)cc(O)c1C2=O</smiles>

Emodin

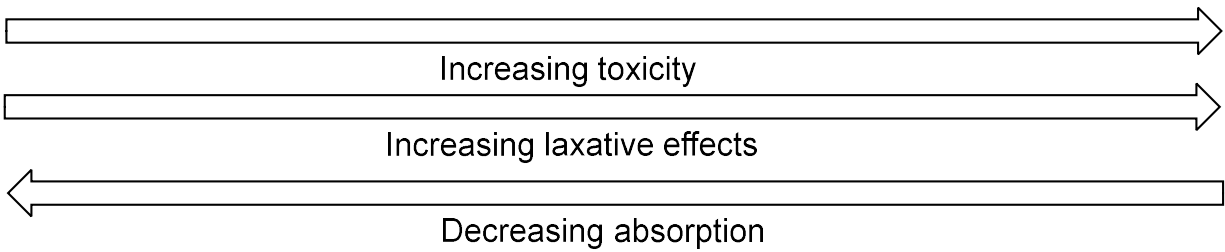

Figure 2: Structure-activity relationships for anthraquinones compounds.

Besides the lack of laxative activity of glucosyl (ox)anthrones, the intestinal metabolism can release the active aglycone. Additionally (ox)anthrones cannot be directly in the extract due to strong side effects, thus the use of glycosylated forms as cascarosides is recommend. Furthermore, the present study shows the safety of their use.

\section{CONCLUSIONS}

In this contribution we establish a relationship between structures of anthraquinones compounds and cytotoxicity. Although aglycones are the most active form, they are responsible for the toxic effects found in anthraquinone-rich extracts. Furthermore, we state that using the glycosylated forms - as the cascarosides - is worthwhile compared to crude extracts, as they prevent direct contact of cells with active forms during intestinal transport. Additionally, absorption is avoided, leading to the need for fewer doses. Besides being inactive, glycosylated anthraquinones can release active aglycones through intestinal bacteria. In the present contribution, we recommend cascarosidesenrichment in cascara extract, although clinical experiments should be conducted to support these findings.

\section{ACKNOWLEDGMENT}

Daniel P. Demarque would like to thank the São Paulo Research Foundation (FAPESP) for the doctoral scholarship (2014/18052-0) and ArboControlBrasil Project, Process TED74/2016 (FNS/UnB). The authors thank the Brazilian foundations FAPESP (2014/50265-3), CNPq, and CAPES.

\section{REFERENCES}

1. Malik EM, Muller CE. Anthraquinones As Pharmacological Tools and Drugs. Med Res Rev. 2016; 36(4): 705-748. doi: 10.1002/med.21391.

2. Song GP, Li SM, Si HZ, Li YB, Li YS, Fan JH, Liang QQ, He HB, Ye HM, Cui ZN. Synthesis and bioactivity of novel xanthone and thioxanthone Lrhamnopyranosides. Rsc Adv. 2015; 5(45): 3609236103. doi: 10.1039/c5ra02846a.

3. Caneque T, Gomes F, Mai TT, Maestri G, Malacria M,Rodriguez R. Synthesis of marmycin A and investigation into its cellular activity. Nat Chem. 2015; 7(9): 744-751. doi: 10.1038/Nchem.2302. 
4. Bockus HL, Willard JH,Bank J. Melanosis coli - The etiologic significance of the anthracene laxatives - A report of forty-one cases. J Amer Med Assoc. 1933; 101: 1-6. doi: 10.1001/jama.1933.02740260003001

5. Walker NI, Bennett RE,Axelsen RA. Melanosis-Coli a Consequence of Anthraquinone-Induced Apoptosis of Colonic Epithelial-Cells. Am J Pathol. 1988; 131(3): 465-476.

6. Badiali D, Marcheggiano A, Pallone F, Paoluzi P, Bausano G, Iannoni C, Materia E, Anzini F,Corazziari E. Melanosis of the Rectum in Patients with Chronic Constipation. Dis Colon Rectum. 1985; 28(4): 241245. doi: 10.1007/Bf02554044.

7. Benavides SH, Morgante PE, Monserrat AJ, Zarate J,Porta EA. The pigment of melanosis coli: a lectin histochemical study. Gastrointest Endosc. 1997; 46(2): 131-138. doi: 10.1016/S0016-5107(97)700609.

8. Chen JY, Pan F, Zhang T, Xia J,Li YJ. Experimental study on the molecular mechanism of anthraquinone cathartics in inducing melanosis coli. Chin J Integr Med. 2011; 17(7): 525-530. doi: 10.1007/s11655-0110786-z.

9. Demarque DP, Pinho DR, Callejon DR, de Oliveira GG, Silva DB, Carollo CA,Lopes NP. New cascarosides from Rhamnus purshiana and fragmentation studies of the class by ion trap mass spectrometry. Rapid Commun Mass Spectrom. 2017; 31(14): 1169-1174. doi: 10.1002/rcm.7883.

10. Sobral LM, Coletta RD, Alberici LC, Curti C,Leopoldino AM. SET/I2PP2A overexpression induces phenotypic, molecular, and metabolic alterations in an oralkeratinocyte cell line. The FEBS Journal. 2017; 284: 2774-2785. doi: 10.1111/febs. 14148 .

11. Goto RN, Sobral LM, Sousa LO, Garcia CB, Lopes NP, Marin-Prida J, Ochoa-Rodriguez E, VerdeciaReyes Y, Pardo-Andreu GL, Curti C, Leopoldino AM. Anti-cancer activity of a new dihydropyridine derivative, VdiE-2N, in head and neck squamous cell carcinoma. Eur J Pharmacol. 2018; 819: 198-206. doi: 10.1016/j.ejphar.2017.12.009.

12. Liao Y, Wang HX, Mao X, Fang HJ, Wang H, Li YR, Sun YJ, Meng C, Tan L, Song CP, Qiu XS, Ding C. $\mathrm{RIP1}$ is a central signaling protein in regulation of TNF-alpha/TRAIL mediated apoptosis and necroptosis during Newcastle disease virus infection. Oncotarget. 2017; 8(26): 43201-43217. doi: 10.18632/oncotarget. 17970.

13. Portt L, Norman G, Clapp C, Greenwood M,Greenwood MT. Anti-apoptosis and cell survival: A review. Bba-Mol Cell Res. 2011; 1813(1): 238-259. doi: 10.1016/j.bbamcr.2010.10.010.

14. Ichim G, Tait SWG. A fate worse than death: apoptosis as an oncogenic process. Nat Rev Cancer. 2016; 16(8): 539-548. doi: 10.1038/nrc.2016.58.

15. Moreau JP, Moreau S,Skinner S. Comparative Physiological Disposition of Some Anthraquinone Glycosides and Aglycones. Biopharm Drug Dispos. 1985; 6(3): 325-334. doi: 10.1002/bdd.2510060307.

16. Kobashi K, Akao T. Relation of Intestinal Bacteria to Pharmacological Effects of Glycosides. Bioscience Microflora. 1997; 16(1): 1-7. doi: 10.12938/bifidus1996.16.1.

17. Hattori M, Kanda T, Shu YZ, Akao T, Kobashi K,Namba T. Metabolism of barbaloin by intestinal bacteria. Chem Pharm Bull (Tokyo). 1988; 36(11): 4462-6. doi: 10.1248/cpb.36.4462

18. de Witte P. Metabolism and pharmacokinetics of anthranoids. Pharmacology. 1993; 47 Suppl 1: 86-97. doi: 10.1159/000139847

19. Akao T, Che Q-M, Kobashi K, Hattori M,Namba T. A purgative action of barboloin is induced by Eubacterium sp. strain BAR, a human intestinal anaerobe, capable of transforming barbaloin to aloeemodin anthrone. Biol Pharm Bull. 1996; 19(1): 136138. doi: $10.1248 / \mathrm{bpb} .19 .136$

20. Dreessen M, Lemli J. Studies in the Field of Drugs Containing Anthraquinone Derivatives .36. The Metabolism of Cascarosides by Intestinal Bacteria. Pharm Acta Helv. 1988; 63(9-10): 287-289. 